\title{
Government social assistance programmes are failing to protect the health of low-income populations: evidence from the USA and Canada (2003-2014)
}

\author{
Faraz Vahid Shahidi, ${ }^{1}$ Odmaa Sod-Erdene, ${ }^{1}$ Chantel Ramraj, ${ }^{1}$ Vincent Hildebrand, ${ }^{1,2}$ \\ Arjumand Siddiqi ${ }^{1,3}$
}

\section{- Additional material is published online only. To view please visit the journal online (http://dx.doi.org/10.1136/ jech-2018-211351) \\ ${ }^{1}$ Dalla Lana School of Public Health, University of Toronto, Toronto, Ontario, Canada ${ }^{2}$ Department of Economics, Glendon College, York University, Toronto, Ontario, Canada \\ ${ }^{3}$ Gillings School of Public Health University of North Carolina,} Chapel Hill, North Carolina, USA

\section{Correspondence to}

Dr Faraz Vahid Shahidi, Dalla Lana School of Public Health, Social and Behavioural Health Sciences Division, University of Toronto, Toronto, ON M5T 3M7, Canada; faraz.vahidshahidi@ utoronto.ca

Received 20 July 2018 Revised 18 September 2018 Accepted 28 October 2018 Published Online First 15 November 2018

\begin{abstract}
Background Social policies that improve the availability and distribution of key socioeconomic resources such as income, wealth and employment are believed to present the most promising avenue for reducing health inequalities. The present study aims to estimate the effect of social assistance recipiency on the health of low-income earners in the USA and Canada. Methods Drawing on nationally representative survey data (National Health Interview Survey and the Canadian Community Health Survey), we employed propensity score matching to match recipients of social assistance to comparable sets of non-recipient 'controls'. Using a variety of matching algorithms, we estimated the treatment effect of social assistance recipiency on selfrated health, chronic conditions, hypertension, obesity, smoking, binge drinking and physical inactivity.

Results After accounting for underlying differences in the demographic and socioeconomic characteristics of recipients and non-recipients, we found that social assistance recipiency was associated with worse health status or, at best, the absence of a clear health advantage. This finding was consistent across several different matching strategies and a diverse range of health outcomes.

Conclusions From a public health perspective, our findings suggest that interventions are warranted to improve the scope and generosity of existing social assistance programmes. This may include reversing welfare reforms implemented over the past several decades, increasing benefit levels and untethering benefit recipiency from stringent work conditionalities.
\end{abstract}

\section{INTRODUCTION}

An extensive body of social epidemiological evidence suggests that health inequalities are largely attributable to inequalities in the distribution of key socioeconomic resources such as income, wealth and employment. ${ }^{2}$ Accordingly, social policies that address the problem of socioeconomic disadvantage are believed to present the most promising avenue for reducing health inequalities. ${ }^{34}$ Social assistance programmes are a principal mechanism by which governments aim to reduce the extent of socioeconomic disadvantage in society. These programmes are designed to provide a modest level of financial assistance to low-income populations. To the extent that they are successful at promoting income security among society's most vulnerable members, they are predicted to contribute to overall population health and health equity. ${ }^{56}$

While public health theory would predict that social assistance programmes are beneficial for the health of the income-insecure, extant studies in this area of research suggest that social assistance recipiency is associated with adverse health outcomes. ${ }^{7-15}$ However, due to a reliance on descriptive methods that are ill equipped to account for selection bias, it is difficult to ascertain whether the negative association reported in these studies is a direct consequence of social assistance or instead reflects a priori differences in the underlying characteristics of recipients and non-recipients. A key challenge in this respect is the need to separate out true programme effects from the potential confounding effects of these underlying differences. ${ }^{16}$ To address this challenge, scholars can exploit a range of techniques that are specifically designed to reduce the risk of confounding. These include such techniques as propensity score matching and synthetic control which, in the absence of an experiment, enable the construction of well-matched 'treatment' and 'control' groups using observational data. ${ }^{17-19}$ Despite their widespread availability, prior work on the health effects of social assistance programmes has neglected to take advantage of these techniques.

In the present study, we employ propensity score matching to investigate the extent to which current social assistance programmes are succeeding at protecting the health of the most income-insecure in the USA and Canada-peer nations with similarly designed social assistance systems. Specifically, we matched recipients of social assistance to comparable sets of non-recipient 'controls' with the aim of estimating the effect of social assistance recipiency on a range of health outcomes.

\section{METHODS}

\section{Data and sample}

Data were obtained from the National Health Interview Survey (NHIS) and the Canadian Community Health Survey (CCHS), the largest nationally representative repeated cross-sectional surveys with information on both health status and social assistance in the USA and Canada, respectively. We pooled survey cycles covering the period from 2003 to 2014. Our sample included individuals 18 to 64 years old, in the lowest decile of household income and active in the labour market (ie, either employed or unemployed and actively seeking work). By 
Table 1 Demographic and socioeconomic characteristics of the unmatched analytic samples

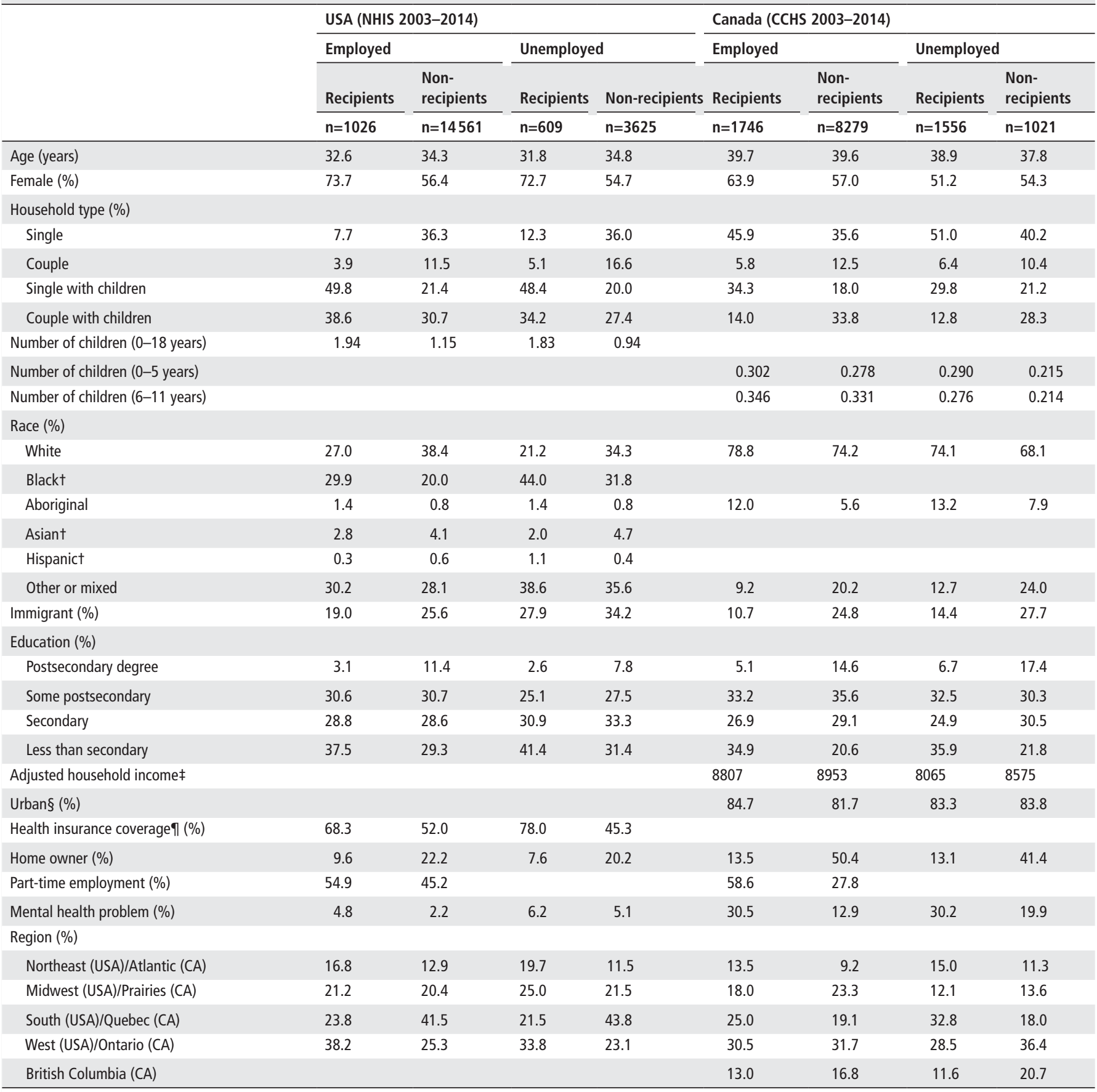

${ }^{*} \mathrm{p}<0.05,{ }^{* *} \mathrm{p}<0.01,{ }^{* * *} \mathrm{p}<0.001$.

tDue to small sample sizes, we were not able to include these categories in the Canadian sample; instead, they are combined with the 'other' category.

$\ddagger$ Continuous income data are not available in the NHIS public microdata file. We were able to identify the lowest decile of NHIS respondents using the available poverty ratio variable.

However, we are unable to describe differences in household income within the lowest decile.

$\S$ The NHIS does not provide a variable to define urban versus rural living.

शDue to universal public healthcare coverage, this variable was not used in the analysis of the CCHS.

NHIS, National Health Interview Survey; CCHS, Canadian Community Health Survey.

limiting our analysis to the lowest income decile, we excluded individuals whose socioeconomic circumstances rendered them ineligible for social assistance, thereby improving the comparability of our recipient and non-recipient groups. We excluded individuals who reported a disability or reported receiving entitlement-based employment insurance. ${ }^{8}{ }^{20}$ We also excluded residents of Canada's three territories, for which equivalised household income information was not available. Because the missing rate for any given variable was relatively low (ie, less than 5\%), we applied listwise deletion to remove observations with missing data. Our final analytic sample included 19821 observations for the USA and 12602 observations for Canada.

\section{Exposure}

In each country, we examined the largest social assistance programmes that provide means-tested cash benefits to individuals who demonstrate both financial need and a willingness to 
work. In the USA, we focused on the federal Temporary Assistance for Needy Families (TANF) programme. In Canada, we focused on the main provincial social assistance programmes (eg, Ontario Works). Because evidence suggests that the effects of social assistance spillover to the entire household, we measured recipiency at the household level. ${ }^{21}$ In the NHIS, a single question asked respondents to indicate whether any member of the household had collected TANF during the preceding year. In the CCHS, a single question asked respondents to indicate whether provincial social assistance was a contributing source to their household income during the preceding year.

\section{Outcomes}

We examined a range of health outcomes. Poor self-rated health was measured using a single five-item Likert scale that asked respondents to rate their general health status. We distinguished between those who reported 'fair' or 'poor' health and those who reported 'excellent', 'very good' or 'good' health. Chronic conditions were measured using a series of questions asking respondents to indicate whether they had ever been diagnosed with any of the following: asthma, emphysema, chronic bronchitis, chronic obstructive pulmonary disease, cancer, diabetes, heart disease or stroke. We distinguished between those who reported having one or more of these conditions and those who reported having none. Hypertension was measured using a single question that asked respondents to indicate whether they had ever been diagnosed with high blood pressure. Obesity was measured using self-reported height and weight variables. Respondents with a body mass index of 30 or above were coded as obese. We also examined a range of health-related risk behaviours, as these may be more sensitive to treatment than harder clinical outcomes. Smoking status was operationalised as daily/occasional or former/non. Alcohol status was operationalised as binge drinker or moderate/non-drinker. Binge drinking was defined as having five or more drinks in a single occasion at least once a month. ${ }^{22}$ Physical activity was operationalised using derived variables which distinguished between respondents who are inactive and those who are at least moderately active.

\section{Predictors}

Our analysis incorporated a range of variables that predict both social assistance recipiency and health status. We included age, sex, family type (single, couple, single with children, couple with children), number of children, self-reported race/ethnicity (white, black, Hispanic, Aboriginal, Asian, other), educational attainment (postsecondary, some postsecondary, secondary, less than secondary), immigrant status, homeownership, urbanicity, health insurance coverage and part-time employment. We further accounted for mental health status, which has been shown to influence selection into social assistance programmes. ${ }^{9} 23$ In Canada, respondents were coded as having a mental health problem if they reported having an anxiety or mood disorder. In the USA, respondents were coded as having a mental health problem if they reported depression, anxiety or an emotional problem. We also accounted for geographical region (Atlantic, Prairies, Quebec, Ontario and British Columbia in Canada; Northeast, Midwest, South and West in the USA).

\section{Analytic strategy}

We began by describing the key characteristics of the sample. Next, we used propensity score matching to estimate the average treatment effect of social assistance on the health of recipientsalso known as the average treatment effect on the treated (ATT). Our main analyses proceeded in two steps. First, a propensity score was derived for each individual. This score is the estimated probability of exposure to treatment conditional on the set of observed characteristics that are known to predict both social assistance recipiency and health status. These are listed above. In the second step, we matched individuals in the exposed and unexposed groups on the propensity score using two matching algorithms: 1:1 calliper matching with replacement (CM) and kernel weighting (KM). These algorithms were selected because they resulted in the most balanced matches. Their key features have been described in detail elsewhere. ${ }^{24}$ We assessed the quality of each match using a series of two-sample t-tests to ensure that matched groups were in fact comparable on the relevant characteristics. With the groups balanced, we attributed any remaining difference in the outcome to treatment status (ie, social assistance recipiency).

We performed three sets of sensitivity analyses to assess the robustness of our findings. Because problematic risk behaviours such as binge drinking predict later life socioeconomic adversity, ${ }^{25}$ they may influence selection into social assistance and confound the association between treatment status and our remaining outcomes. We therefore ran a complete set of supplementary analyses in which risk behaviours (ie, binge drinking, smoking and physical inactivity) were included in the pool of confounders used to estimate the propensity score. We also

Table 2 Health-related characteristics of the unmatched analytic samples

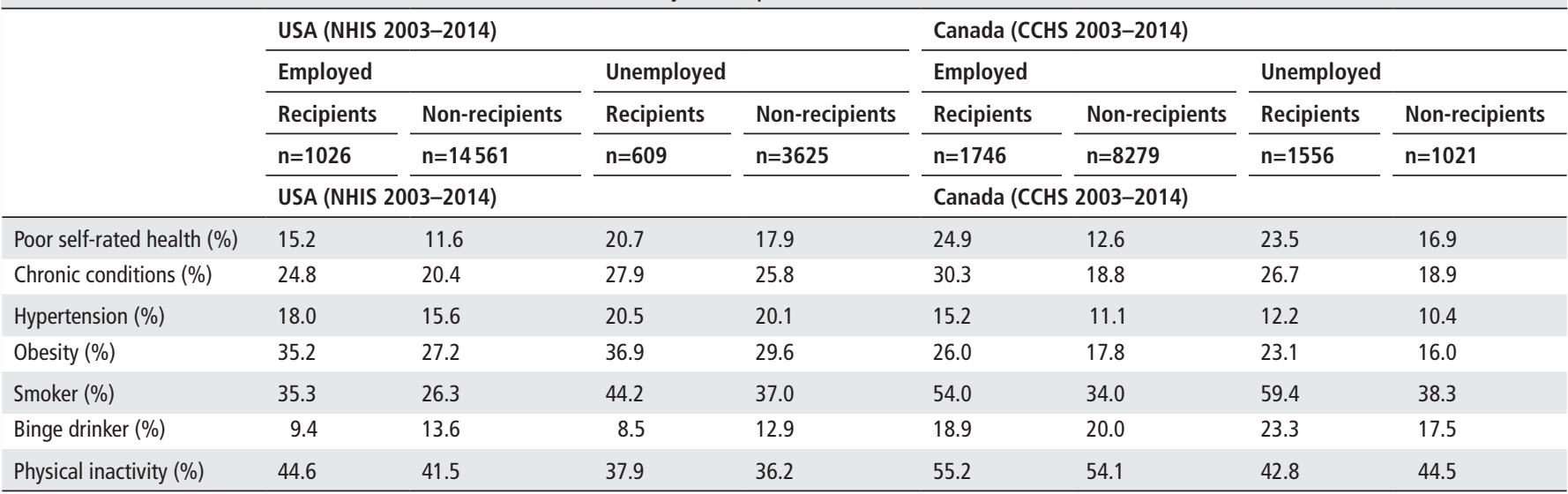

${ }^{*} \mathrm{p}<0.05,{ }^{* *} \mathrm{p}<0.01,{ }^{* * *} \mathrm{p}<0.001$

NHIS, National Health Interview Survey; CCHS, Canadian Community Health Survey. 


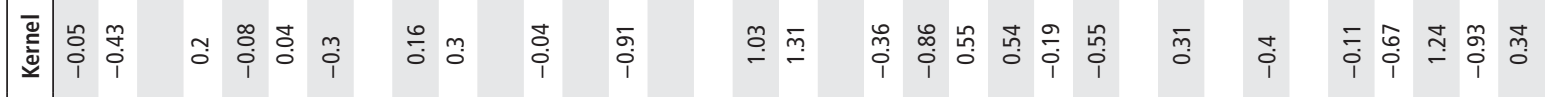

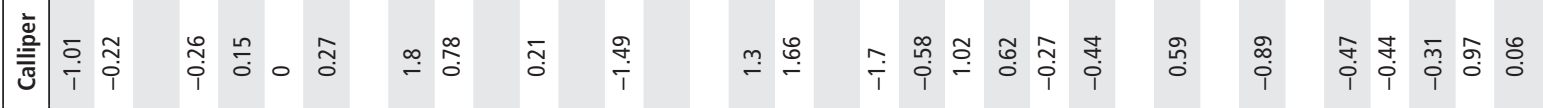

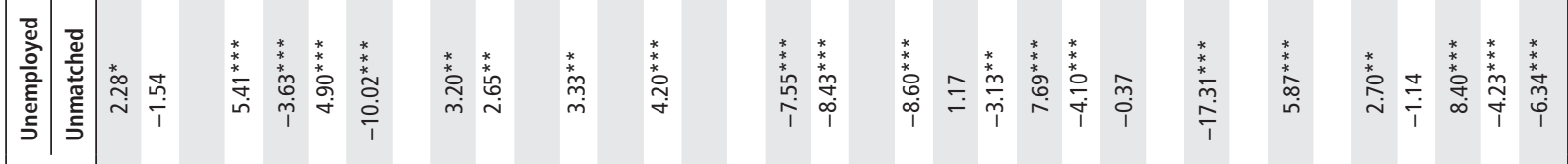

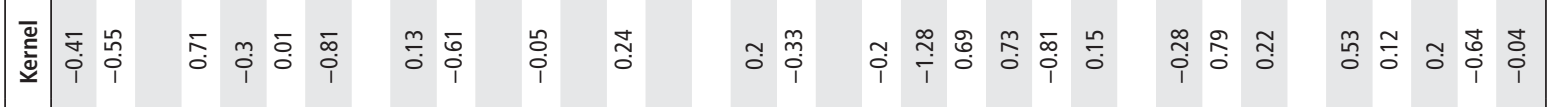
商

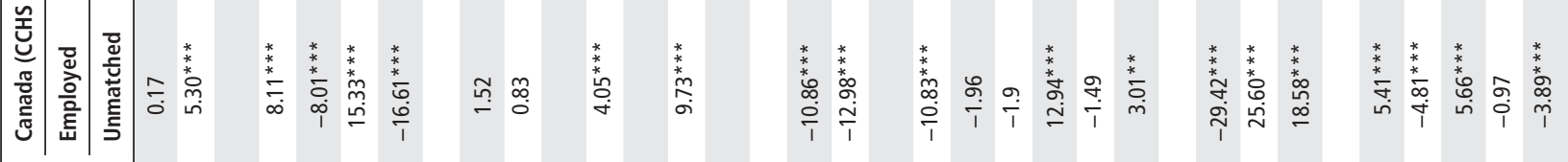

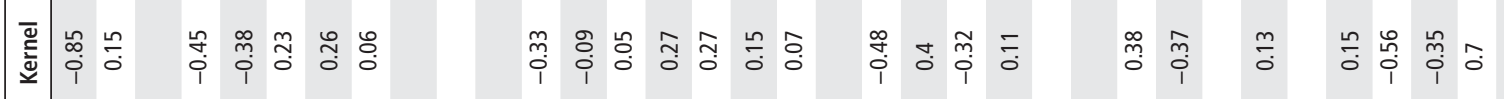

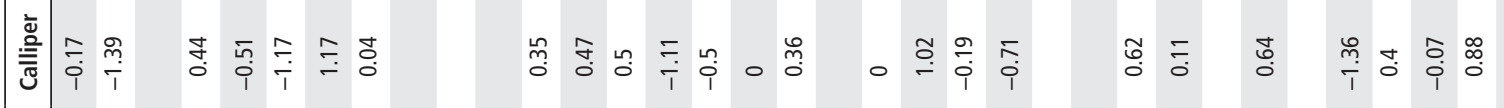

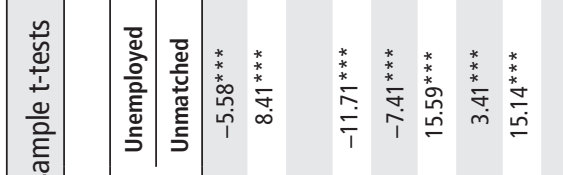

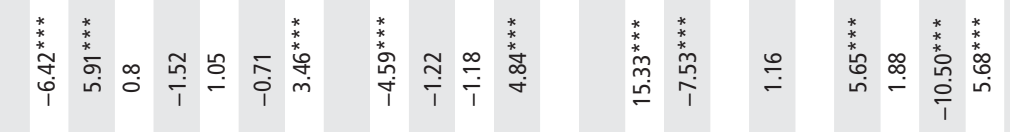

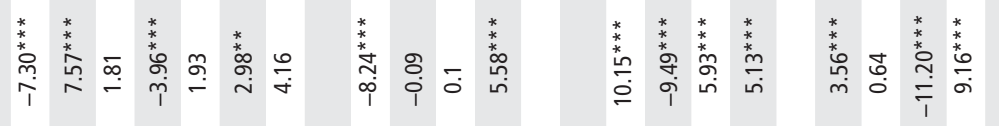

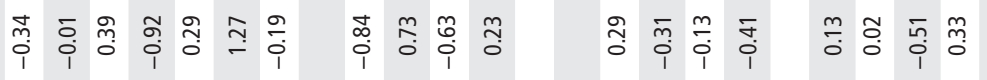

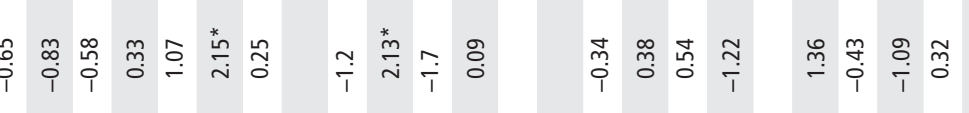

Research report

(1)


Table 4 Average treatment effects on the treated: American social assistance recipients (NHIS 2003-2014)

\begin{tabular}{|c|c|c|c|c|c|c|}
\hline & \multicolumn{3}{|l|}{ Employed } & \multicolumn{3}{|l|}{ Unemployed } \\
\hline & Prevalence difference & SE & $P$ values & Prevalence difference & SE & $P$ values \\
\hline \multicolumn{7}{|l|}{ Poor self-rated health } \\
\hline Calliper matching $\dagger$ & 0.022 & 0.021 & 0.287 & 0.046 & 0.027 & 0.090 \\
\hline Kernel weighting & $0.032^{*}$ & 0.014 & 0.029 & $0.039^{*}$ & 0.020 & 0.046 \\
\hline \multicolumn{7}{|l|}{ Hypertension } \\
\hline Calliper matching $\dagger$ & $0.044^{*}$ & 0.020 & 0.031 & -0.012 & 0.027 & 0.664 \\
\hline Kernel weighting & $0.027^{*}$ & 0.013 & 0.042 & 0.014 & 0.019 & 0.466 \\
\hline \multicolumn{7}{|l|}{ Chronic conditions } \\
\hline Calliper matching $\dagger$ & 0.022 & 0.020 & 0.261 & 0.037 & 0.031 & 0.226 \\
\hline Kernel weighting & $0.031^{*}$ & 0.016 & 0.047 & 0.020 & 0.021 & 0.343 \\
\hline \multicolumn{7}{|l|}{ Smoking } \\
\hline Calliper matching $\dagger$ & $0.073^{* *}$ & 0.025 & 0.003 & 0.053 & 0.038 & 0.165 \\
\hline Kernel weighting & $0.069^{* * *}$ & 0.016 & 0.000 & $0.063^{* *}$ & 0.024 & 0.010 \\
\hline \multicolumn{7}{|l|}{ Binge drinking } \\
\hline Calliper matching $\dagger$ & $0.028^{*}$ & 0.133 & 0.034 & -0.007 & 0.021 & 0.743 \\
\hline Kernel weighting & 0.005 & 0.011 & 0.559 & -0.003 & 0.015 & 0.846 \\
\hline \multicolumn{7}{|l|}{ Physical inactivity } \\
\hline Calliper matching $\dagger$ & -0.003 & 0.028 & 0.914 & -0.048 & 0.037 & 0.200 \\
\hline Kernel weighting & -0.014 & 0.017 & 0.384 & -0.003 & 0.027 & 0.910 \\
\hline \multicolumn{7}{|l|}{ Obesity } \\
\hline Calliper matching $\dagger$ & 0.030 & 0.024 & 0.216 & 0.012 & 0.033 & 0.716 \\
\hline Kernel weighting & 0.027 & 0.017 & 0.106 & 0.022 & 0.022 & 0.321 \\
\hline \multicolumn{7}{|l|}{ Sample size } \\
\hline Unmatched & \multicolumn{3}{|c|}{ Recipients=1026 Control=14561 } & \multicolumn{3}{|c|}{ Recipients $=609$ Control $=3625$} \\
\hline Calliper matching $\dagger$ & \multicolumn{3}{|c|}{ Recipients $=994$ Control $=855$} & \multicolumn{3}{|c|}{ Recipients=589 Control=435 } \\
\hline Kernel weighting & \multicolumn{3}{|c|}{ Recipients $=998$ Control $=14264$} & \multicolumn{3}{|c|}{ Recipients $=603$ Control $=3625$} \\
\hline
\end{tabular}

${ }^{*} \mathrm{p}<0.05,{ }^{* *} \mathrm{p}<0.01,{ }^{* * *} \mathrm{p}<0.001$.

tCalliper is set to 0.015 ; narrower than the 0.2 of the SD of the logit of the propensity score recommended by Austin. ${ }^{18}$

NHIS, National Health Interview Survey.

conducted additional models using an extensive set of alternative matching algorithms, including simple nearest neighbour matching, calliper matching without replacement, radius matching with different radius values and local linear matching. Finally, we ran sensitivity analyses in which social assistance recipiency was measured at the person level rather than the household level.

Due to potential differences in characteristics and treatment effects across labour market groups, we stratified all our analyses by employment status. All analyses were conducted in Stata V.13.0 (StataCorp). Two principal Stata commands were used: pscore and psmatch2. A full example of our code is included in the online appendix accompanying this article. ATTs are reported in the text with their corresponding SE.

\section{Limitations of the analytic strategy}

Our estimation strategy aims to account for observable characteristics that are known to confound the relationship between social assistance and health. However, our results may be biased by unknown confounders. Furthermore, due to limitations of the available survey data, we could not account for several known confounders, such as wealth, savings, family support and other unmeasured sources of material support, that differ systematically between recipients and non-recipients. Nevertheless, by restricting our sample to observations in the lowest decile of income, we take an important step towards reducing this potential selection problem. A related limitation concerns the secondary functions of social assistance programmes as gateways to ancillary services, such as Medicaid in the USA or supplemental drug and dental coverage in Canada. To the extent that an individual's propensity to seek out ancillary coverage is likely to vary as a function of health status, these secondary functions may be operating as an additional source of bias. Again, due to limitations of the data, we were unable to account for this potential selection problem. Finally, many of our variables rely on self-report and are therefore subject to the corresponding biases.

\section{RESULTS}

\section{Descriptive characteristics}

We describe the key characteristics of the sample in table 1 and table 2. Compared with non-recipients, social assistance recipients in both the USA and Canada were more likely to be women, more likely to have children and less likely to be immigrants. Whereas a greater proportion of recipients belonged to visible minority groups in the USA, recipients in Canada were more likely than their non-recipient counterparts to identify as white. In the USA, recipients were more likely than non-recipients to have health insurance coverage. In the USA and to a greater extent in Canada, employed recipients were much more likely than non-recipients to be in part-time employment. In both 
Table 5 Average treatment effects on the treated: Canadian social assistance recipients (CCHS 2003-2014)

\begin{tabular}{|c|c|c|c|c|c|c|}
\hline & \multicolumn{3}{|l|}{ Employed } & \multicolumn{3}{|l|}{ Unemployed } \\
\hline & Prevalence difference & SE & $P$ values & Prevalence difference & SE & $P$ values \\
\hline \multicolumn{7}{|l|}{ Poor self-rated health } \\
\hline Calliper matching $\dagger$ & $0.079^{* * *}$ & 0.017 & 0.000 & 0.013 & 0.024 & 0.596 \\
\hline Kernel weighting & $0.068 * * *$ & 0.013 & 0.000 & 0.029 & 0.022 & 0.186 \\
\hline \multicolumn{7}{|l|}{ Hypertension } \\
\hline Calliper matching $\dagger$ & $0.034^{*}$ & 0.017 & 0.043 & -0.016 & 0.021 & 0.450 \\
\hline Kernel weighting & 0.019 & 0.012 & 0.107 & -0.002 & 0.018 & 0.914 \\
\hline \multicolumn{7}{|l|}{ Chronic conditions } \\
\hline Calliper matching $\dagger$ & $0.051^{* *}$ & 0.019 & 0.007 & $0.067^{*}$ & 0.027 & 0.012 \\
\hline Kernel weighting & $0.067^{* * *}$ & 0.014 & 0.000 & $0.054^{*}$ & 0.023 & 0.019 \\
\hline \multicolumn{7}{|l|}{ Smoking } \\
\hline Calliper matching $\dagger$ & $0.078^{* * *}$ & 0.022 & 0.000 & 0.053 & 0.029 & 0.070 \\
\hline Kernel weighting & $0.079^{* * *}$ & 0.016 & 0.000 & $0.060^{* *}$ & 0.023 & 0.010 \\
\hline \multicolumn{7}{|l|}{ Binge drinking } \\
\hline Calliper matching $\dagger$ & -0.025 & 0.017 & 0.134 & 0.034 & 0.025 & 0.169 \\
\hline Kernel weighting & $-0.024^{*}$ & 0.012 & 0.043 & 0.030 & 0.021 & 0.140 \\
\hline \multicolumn{7}{|l|}{ Physical inactivity } \\
\hline Calliper matching $\dagger$ & 0.001 & 0.021 & 0.956 & -0.035 & 0.029 & 0.230 \\
\hline Kernel weighting & -0.003 & 0.014 & 0.824 & -0.035 & 0.028 & 0.210 \\
\hline \multicolumn{7}{|l|}{ Obesity } \\
\hline Calliper matching $\dagger$ & $0.054^{* *}$ & 0.018 & 0.003 & 0.028 & 0.022 & 0.206 \\
\hline Kernel weighting & $0.063^{* * *}$ & 0.012 & 0.000 & $0.048^{*}$ & 0.019 & 0.012 \\
\hline \multicolumn{7}{|l|}{ Sample size } \\
\hline Unmatched & \multicolumn{3}{|c|}{ Recipients $=1746$ Non-recipients $=8279$} & \multicolumn{3}{|c|}{ Recipients $=1556$ Non-recipients $=1021$} \\
\hline Calliper matching $\dagger$ & \multicolumn{3}{|c|}{ Recipients $=1720$ ‡ Non-recipients $=1190$} & \multicolumn{3}{|c|}{ Recipients $=1480 \ddagger$ Non-recipients $=503$} \\
\hline Kernel weighting & \multicolumn{3}{|c|}{ Recipients $=1740 \ddagger$ Non-recipients $=8279$} & \multicolumn{3}{|c|}{ Recipients $=1550 \neq$ Non-recipients $=1021$} \\
\hline
\end{tabular}

${ }^{*} \mathrm{p}<0.05,{ }^{* *} \mathrm{p}<0.01,{ }^{* * *} \mathrm{p}<0.001$.

tCalliper is set to 0.015 ; narrower than the 0.2 of the SD of the logit of the propensity score recommended by Austin. ${ }^{18}$

¥Due to administrative restrictions imposed by Statistics Canada, these values are rounded.

CCHS, Canadian Community Health Survey.

countries, recipients reported worse socioeconomic profiles than non-recipient, including lower levels of educational attainment and lower rates of home ownership. Social assistance recipients also reported consistently worse health outcomes.

\section{Propensity score matching}

Prior to matching, we observed significant differences in the underlying characteristics of social assistance recipients and their non-recipient counterparts. These differences were no longer significant after matching, as evidenced by the postmatch balance tests reported in table 3, which indicate satisfactory balance on these characteristics.

Treatment effects as well as the number of observations selected in each match are reported in table 4 and table 5. For a description of the range and distribution of the estimated propensity score, see online supplementary table 1 and online supplementary figure 1 of the online appendix. After matching on the propensity score, social assistance recipients in both the USA and Canada reported similar or worse health outcomes than matched non-recipients. In the USA, employed social assistance recipients reported higher rates of poor self-rated health (CM: ATT 2.2\%, SE 0.021; KW: ATT 3.2\%, SE 0.014), chronic conditions (CM: ATT 3.1\%, SE 0.016; KW: ATT 2.2\%, SE 0.020), hypertension (CM: ATT 4.4\%, SE 0.020; KW: ATT 2.7\%, SE $0.013)$, smoking (CM: ATT 6.9\%, SE 0.016; KW: ATT 7.3\%, SE 0.025$)$ and binge drinking (CM: ATT 0.5\%, SE 0.011; KW:
ATT 2.8\%, SE 0.133) than matched controls. The ATTs reported for hypertension and smoking were statistically significant across both matching specifications, while the ATTs for poor self-rated health and chronic conditions were only significant using the kernel method, and the ATT for binge drinking was only significant using the calliper method. Unemployed social assistance recipients reported higher rates of poor self-rated health (CM: ATT 4.6\%, SE 0.027; KW: ATT 3.9\%, SE 0.020) and smoking (CM: ATT 5.3\%, SE 0.038; KW: ATT 6.3\%, SE 0.024) than matched controls, though these ATTs were only significant using kernel matching. Differences in the remaining outcomes were not statistically significant.

In Canada, employed social assistance recipients reported higher rates of poor self-rated health (CM: ATT 7.9\%, SE 0.017; KW: ATT 6.8\%, SE 0.013) chronic conditions (CM: ATT 5.1\%, SE 0.019; KW: ATT 6.7\%, SE 0.014), hypertension (CM: ATT 3.4\%, SE 0.017; KW: ATT 1.9\%, SE 0.012), obesity (CM: ATT 5.4\%, SE 0.018; KW: ATT 6.3\%, SE 0.012), smoking (CM: ATT 7.8\%, SE 0.022; KW: ATT 7.9\%, SE 0.016) and binge drinking (CM: ATT 2.5\%, SE 0.017; KW: ATT 2.4\%, SE 0.012). In most cases, these ATTs were statistically significant across both matching specifications. Unemployed social assistance recipients reported higher rates of chronic conditions (CM: ATT 6.7\%, SE 0.027; KW: ATT 5.4\%, SE 0.023), obesity (CM: ATT 2.8\%, SE 0.022; KW: ATT 4.8\%, SE 0.019) and smoking (CM: ATT 5.3\%, SE 0.028; KW: ATT 6.0\%, SE 0.023). The ATT 
for chronic conditions was statistically significant across both matching specifications, while the ATTs for obesity and smoking were only significant using the kernel method. Differences in the remaining outcomes were not statistically significant.

Supplementary analyses in which we treated risk behaviours (ie, binge drinking, smoking and physical inactivity) as confounders, rather than outcomes, produced very similar results. These additional results are reported in online supplementary table 2 and online supplementary table 3 of the online appendix. Supplementary models (not shown) in which we employed an extensive set of alternative matching algorithms and measured social assistance recipiency at the person level rather than the household level revealed that our results are robust across these key analytic decisions.

\section{DISCUSSION}

Analytic models in which we carefully controlled for socioeconomic and other differences between social assistance recipients and non-recipients demonstrated that in most cases, receipt of social assistance was associated with worse health status, and at best, with no effect on health status. This finding held true across several different matching strategies and a diverse range of outcomes. Contrary to public health theorywhich would predict that social assistance policies confer a benefit to the health of the income-insecure-and despite conducting the most rigorous possible comparisons given the available data, these results are consonant with the existing literature from the USA, ${ }^{8-10} 1213$ Canada $^{15}$ and peer nations in Europe. 71114

On the surface, these results might lend support to the notion that providing benefits is inherently problematic for health. However, based on a vast body of literature that substantiates the benefits of increased income for the socioeconomically vulnerable, such an explanation would appear to lack merit. ${ }^{1-4}$ Rather, there are other far more plausible explanations worth considering. It may be the case, for example, that the level of income support currently provided by social assistance programmes are insufficient to adequately buffer the adverse consequences of income insecurity. In both the USA and Canada, the generosity of social assistance programmes was severely curtailed in the 1990s. ${ }^{272}$ Governments have undertaken little legislative effort since that time to increase benefit levels or allow them to keep up with rising costs of living. ${ }^{29} 30$ As a result, the socioeconomic circumstances of recipients are lagging further and further behind that of their more advantaged counterparts. This may provide a powerful explanation for our study findings and for broader evidence that health inequalities between socioeconomic groups are widening over time.

Work conditionalities attached to the receipt of social assistance provide another possible explanation for our findings. In order to maintain programme eligibility, social assistance recipients are expected to meet an increasingly strict set of requirements that compel labour market participation. ${ }^{31}$ While these measures have succeeded at increasing employment rates among social assistance recipients, their attachment to the labour market tends to be marginal, short-lived and involve the uptake of low paying, poorly protected jobs. ${ }^{32-35}$ Recent evidence suggests that these precarious jobs may pose an equal or even greater risk to health than unemployment. ${ }^{36-39}$ Programme conditionalities that compel entry into precarious labour market arrangements may offset the potential health benefits of social assistance, and thus may in part explain why we have failed to find evidence of a protective effect associated with recipiency.
Finally, though we carefully controlled for many of the most notable sources of confounding, our results may reflect unaccounted for selection effects that differentiate social assistance recipients from non-recipients, thus making for problematic comparisons. For example, in the context of social assistance programmes providing a gateway to ancillary benefits that are not universally available (eg, health insurance), our results may reflect a propensity for people who are sicker to select into social assistance. ${ }^{40}$ In a similar vein, individuals with unmeasured sources of wealth or family support may opt out of or be ineligible for social assistance. Unfortunately, we lack the data necessary to take account of these additional factors. In both cases, however, they are likely to bias findings towards a negative association between social assistance recipiency and health.

\section{CONCLUSIONS}

The results of our study were remarkably consistent across jurisdictions, health outcomes and model specifications: the receipt of social assistance is associated with poorer health status or, at best, the absence of a clear health advantage, even after controlling for alternative explanations such as differences in the demographic and socioeconomic characteristics of recipients and non-recipients. With significant evidence that social assistance programmes have not kept up with the cost of living, these findings lend support for the notion, at least from a public health perspective, that interventions are warranted that will improve the generosity of existing social assistance programmes. This may include reversing welfare reforms implemented over the past several decades, increasing benefit rates and untethering benefit recipiency from work conditionalities.

\section{What is already known on this subject}

Social assistance programmes are designed to provide income supplementation to socioeconomically disadvantaged populations.

- Social assistance recipiency is associated with adverse health outcomes.

- Prior studies have not used the best available methods to disentangle policy effects from underlying differences between social assistance recipients and non-recipient comparison groups.

\section{What this study adds}

- We employed propensity score methods to match social assistance recipients to comparable non-recipient 'controls' and estimated the effect of recipiency on a range of health outcomes in Canada and the USA.

- After carefully controlling for demographic and socioeconomic differences between recipients and nonrecipient 'controls', social assistance recipiency was associated with worse health outcomes or, at best, no clear health advantage.

- Our study findings support the notion that interventions are warranted that will improve the scope and generosity of existing social assistance programmes. 
Contributors FVS, OS-E, CR, VH, AS: planned and conceptualised the study. FVS, OS-E: acquired and analysed the data. FVS, OS-E, CR, VH, AS: interpreted the data, wrote the manuscript and revised it critically for intellectual context. All authors approved the final manuscript as submitted and agree to be accountable for all aspects of the work.

Funding AS is supported by the Canada Research Chair in Population Health Equity. The study was partially funded by the Ontario Ministry of Community and Social Services.

Competing interests None declared.

Patient consent Not required.

Ethics approval Ethics approval was not required, as the study relied on deidentified secondary survey data available publicly through the National Center for Health Statistics (NHIS) or by review and approval through Statistics Canada (CCHS)

Provenance and peer review Not commissioned; externally peer reviewed.

Data sharing statement NHIS data are publicly available through the National Center for Health Statistics (www.cdc.gov/nchs) CCHS data are available through formal request by eligible researchers to the Statistics Canada Research Data Centre Network (www.crden.org).

\section{REFERENCES}

1 Braveman P, Egerter S, Williams DR. The social determinants of health: coming of age. Annu Rev Public Health 2011;32:381-98.

2 Marmot M, Friel S, Bell R, et al. Closing the gap in a generation: health equity through action on the social determinants of health. Lancet 2008:372:1661-9.

3 Braveman P, Gottlieb L. The social determinants of health: it's time to consider the causes of the causes. Public Health Rep 2014;129:19-31.

4 Solar $\mathrm{O}$, Irwin A. A conceptual framework for action on the social determinants of health. Geneva: World Health Organization, 2010.

5 Lundberg O, Fritzell J, Åberg Yngwe M, et al. The potential power of social policy programmes: income redistribution, economic resources and health. Int I Soc Welf 2010;19:S2-13.

6 Nelson K, Fritzell J. Welfare states and population health: the role of minimum income benefits for mortality. Soc Sci Med 2014;112:63-71.

7 Baigi A, Lindgren EC, Starrin B, et al. In the shadow of the welfare society ill-health and symptoms, psychological exposure and lifestyle habits among social security recipients: a national survey study. Biopsychosoc Med 2008;2:15.

8 Danziger SK, Kalil A, Anderson NJ. Human Capital, Physical Health, and Mental Health of Welfare Recipients: Co-occurrence and Correlates. J Soc Issues 2000;56:635-54.

9 Dooley D, Prause J. Mental health and welfare transitions: depression and alcohol abuse in AFDC women. Am J Community Psychol 2002;30:787-813.

10 Kaplan GA, Siefert K, Ranjit N, et al. The health of poor women under welfare reform. Am J Public Health 2005;95:1252-8.

11 Ford E, Clark C, McManus S, et al. Common mental disorders, unemployment and welfare benefits in England. Public Health 2010;124:675-81.

12 Jayakody R, Danziger S, Pollack H. Welfare reform, substance use, and mental health. J Health Polit Policy Law 2000;25:623-52.

13 Ensminger ME, Juon HS. The influence of patterns of welfare receipt during the child-rearing years on later physical and psychological health. Women Health 2001;32:25-46.

14 Løyland B, Miaskowski C, Dahl E, et al. Psychological distress and quality of life in long-term social assistance recipients compared to the Norwegian population. Scand J Public Health 2011;39:303-11.

15 Vozoris NT, Tarasuk VS. The health of Canadians on welfare. Can J Public Health 2004;95:115-20.
16 Grimes DA, Schulz KF. Bias and causal associations in observational research. Lancet 2002;359:248-52.

17 Basu S, Meghani A, Siddiqi A. Evaluating the health impact of large-scale public policy changes: classical and novel approaches. Annu Rev Public Health 2017;38:351-70.

18 Austin PC. An introduction to propensity score methods for reducing the effects of confounding in observational studies. Multivariate Behav Res 2011;46:399-424.

19 Rubin DB. Matched sampling for causal effects. Cambridge: Cambridge University Press, 2006.

20 Rodriguez E. Keeping the unemployed healthy: the effect of means-tested and entitlement benefits in Britain, Germany, and the United States. Am J Public Health 2001:91:1403-11.

21 Bonke J. Pooling of income and sharing of consumption within households. Rev Econ Househ 2015:13:73-93.

22 Substance Abuse and Mental Health Services Administration. Binge drinking: terminology and patterns of use. Rockville (MD): Substance Abuse and Mental Health Services Administration, 2016.

23 Kiely KM, Butterworth P. Mental health selection and income support dynamics: multiple spell discrete-time survival analyses of welfare receipt. J Epidemiol Community Health 2014;68:349-55.

24 Caliendo M, Kopeinig S. Some practical guidance for the implementation of propensity score matching. J Econ Surv 2008;22:31-72.

25 Tucker JS, Orlando M, Ellickson PL. Patterns and correlates of binge drinking trajectories from early adolescence to young adulthood. Health Psychol 2003;22:79-87.

26 Viner RM, Taylor B. Adult outcomes of binge drinking in adolescence: findings from a UK national birth cohort. J Epidemiol Community Health 2007:61:902-7.

27 Béland D, Daigneault PM. Welfare reform in Canada: provincial social assistance in comparative perspective. Toronto: University of Toronto Press, 2015.

28 Grogger J, Karoly LA GK. Welfare reform: effects of a decade of change. Harvard (MA): Harvard University Press, 2005

29 Floyd I. TANF cash benefits have fallen by more than 20 percent in most states and continue to Erode. 2017 [Internet]. Washington, DC: Center on Budget and Policy Priorities, 2017.

30 Tiessen K. Ontario's social assistance poverty gap. Ottawa: Canadian Centre for Policy Alternatives, 2016

31 Anderson T, Kairys K, Wiseman M. Activation and reform in the united states: what time has told. Oxford: Oxford University Press, 2014.

32 Morgen S, Acker J, Weight J. Stretched thin: poor families, welfare work, and welfare reform. Ithaca (NY): Cornell University Press, 2009.

33 Kalleberg AL. Precarious lives: job insecurity and well-being in rich democracies. London: Wiley, 2018.

34 Kilty KM, Segal EA. The promise of welfare reform: political rhetoric and the reality of poverty in the twenty-first century. London: Routledge, 2012.

35 Blank RM, Danziger S, Schoeni RF. Working and poor: how economic and policy changes are affecting low-wage workers. New York (NY: Russell Sage Foundation, 2007.

36 Benach J, Vives A, Amable M, et al. Precarious employment: understanding an emerging social determinant of health. Annu Rev Public Health 2014;35:229-53.

37 Butterworth P, Leach LS, McManus S, et al. Common mental disorders, unemployment and psychosocial job quality: is a poor job better than no job at all? Psychol Med 2013;43:1763-72.

38 Chandola T, Zhang N. Re-employment, job quality, health and allostatic load biomarkers: prospective evidence from the UK Household Longitudinal Study. Int $J$ Epidemiol 2018;47:47-57.

39 Broom DH, D'Souza RM, Strazdins L, et al. The lesser evil: bad jobs or unemployment? A survey of mid-aged Australians. Soc Sci Med 2006;63:575-86.

40 Currie J, Grogger J. Medicaid expansions and welfare contractions: offsetting effects on prenatal care and infant health? J Health Econ 2002;21:313-35. 